\title{
Establishment and Application of the Wind and Structural Health Monitoring System for the Runyang Yangtze River Bridge
}

\author{
Hao Wang, ${ }^{1,2}$ Aiqun Li, ${ }^{1,2}$ Tong Guo, ${ }^{1,2}$ and Tianyou Tao ${ }^{1,2}$ \\ ${ }^{1}$ Key Laboratory of C\&PC Structures of Ministry of Education, Southeast University, Nanjing 210096, China \\ ${ }^{2}$ School of Civil Engineering, Southeast University, Nanjing 210096, China \\ Correspondence should be addressed to Hao Wang; wanghao1980@seu.edu.cn and Aiqun Li; aiqunli@seu.edu.cn
}

Received 16 June 2014; Accepted 11 August 2014; Published 27 August 2014

Academic Editor: Bo Chen

Copyright ( $\odot 2014$ Hao Wang et al. This is an open access article distributed under the Creative Commons Attribution License, which permits unrestricted use, distribution, and reproduction in any medium, provided the original work is properly cited.

\begin{abstract}
Structural health monitoring can provide a practical platform for detecting the evolution of structural damage or performance deterioration of engineering structures. The final objective is to provide reasonable suggestions for structural maintenance and management and therefore ensure the structural safety according to the real-time recorded data. In this paper, the establishment of the wind and structural health monitoring system (WSHMS) implemented on the Runyang Yangtze River Bridge (RYRB) in China is introduced. The composition and functions of the WSHMS are presented. Thereinto, the sensory subsystem utilized to measure the input actions and structural output responses is introduced. And the core functions of the data management and analysis subsystem (DMAS) including model updating, structural condition identification, and structural condition assessment are illustrated in detail. A three-stage strategy is applied into the FE model updating of RYRB, and a two-phase strategy is proposed to adapt to structural health diagnosis and damage identification. Considering the structural integral security and the fatigue characteristic of steel material, the condition assessment of RYRB is divided into structural reliability assessment and structural fatigue assessment, which are equipped with specific and elaborate module for effective operation. This research can provide references for the establishment of the similar structural health monitoring systems on other cable-supported bridges.
\end{abstract}

\section{Introduction}

Bridges represent a key element in terms of the safety and functionality of the entire transportation system. With the worldwide development of transportation, numerous longspan bridges have been constructed to cross wide rivers, seas, or canyons. Due to its prominent spanning capacity and explicit mechanical behaviors, the cable-supported bridge exhibits as one of the most suitable selections among longspan bridges. There are a lot of famous cable-supported bridges implemented all over the world, such as the Akashi Kaikyo Suspension Bridge (1991 m) in Japan, the Great Belt Suspension Bridge $(1624 \mathrm{~m})$ in Denmark, and the Russky Island Cable-Stayed Bridge $(1104 \mathrm{~m})$ in Russia. In China, a great many long-span cable-supported bridges have also been in operation over the Yangtze River, canyons in the western area, and seas in the eastern region, such as Runyang
Suspension Bridge $(1490 \mathrm{~m})$, Sutong Cable-Stayed Bridge (1088 m), Jiangyin Suspension Bridge $(1385 \mathrm{~m})$, and Aizhai Suspension Bridge (1176 m).

In their long service periods of several decades or over 100 years, the long-span bridges are inevitable to encounter the long-term loads, fatigue effects, material aging, coupling effects with extreme loads, environmental corrosion, and so forth [1-3]. Subjected to natural actions including serious environmental corrosion, earthquakes, typhoons, thunderstorms, tornados, and so forth, the cable-supported bridge with flexible characteristics may suffer from slow performance deteriorations, severe structural damage, and even collapse in different scales. In addition, the structural performance deterioration will be further aggravated by the continuous increase of traffic loads. All of these factors can lead to the decrease of load bearing capacity and durability of the bridges and therefore influence the safety of structures. 


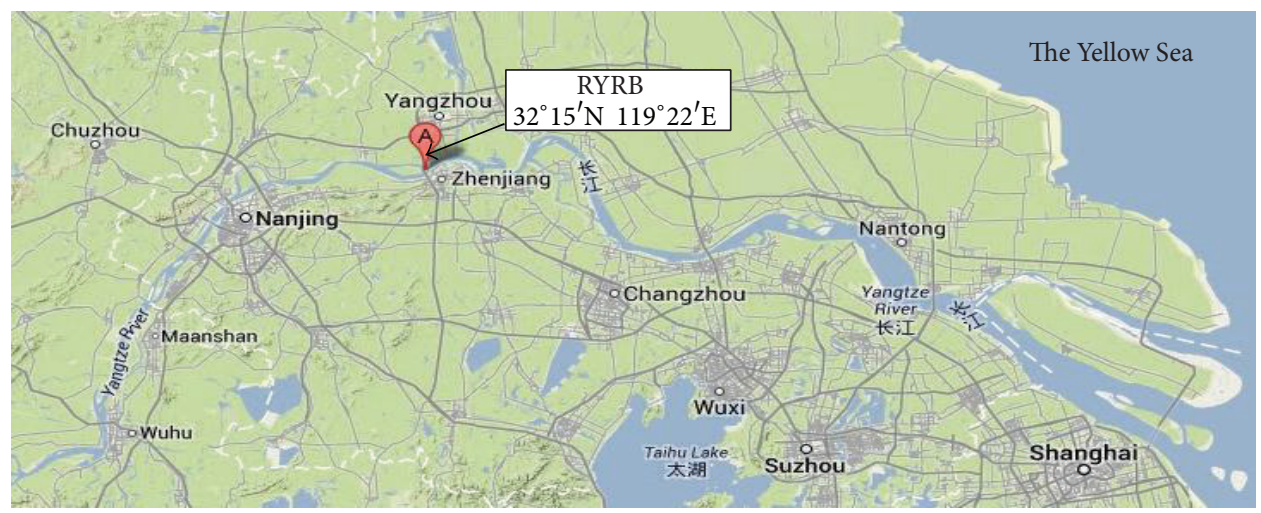

FIGURE 1: Geographical location of RYRB.

As a result, the health status, durability, and safety of the cable-supported bridges in their long-term service periods attract intensive attentions from the government and civil engineers.

In order to ensure the structural serviceability and sustainability, the structural health monitoring system (SHMS) provides an efficient approach to evaluate the safety and durability of a structure during its service life [2-8]. The SHMS usually contains a sensor system, a data acquisition system, a data transmission system, and a data management system. And the SHMS is equipped with two main functions in general. Firstly, a structure installed with a SHMS can be considered as a full-scale experimental platform. The measured environmental loads such as earthquake ground motions, wind speed, wind pressure, vehicles, temperature, and humidity would help understand the environment around the cable-supported bridges and enhance the structural response prediction capabilities. Secondly, the model updating, condition identification, condition assessment, and decision making of long-span cable-supported bridges can be further conducted based on the measured structural responses. Therefore, the SHMS of cable-supported bridges in real time offers the potential to reduce inspection and repair costs, as well as the associated downtime, all while providing increased public safety [9].

Among the various kinds of environmental loads, wind, earthquake, and vehicles play dominant roles on the cablesupported bridges, which may result in severe structural damage or even collapse. For cable-supported bridges constructed in the eastern coastal area of China, wind loads play an important role in their whole-life design due to the distinctive alternate typhoon and strong north wind climate every year. Compared with the comparatively infrequent earthquakes, typhoons in summer and strong north wind in winter will act on these wind-sensitive cable-supported bridges in the eastern costal region frequently. Therefore, the wind environment around the bridge site needs to be emphatically monitored by the wind and structural health monitoring system (WSHMS), to assure the structural function properly during their long service lives and to prevent them from sudden failure or fatal disaster during strong winds $[10,11]$.
This paper presents a study on the establishment of the WSHMS for the super-long-span cable-supported bridges existing in hostile environment where typhoon, hurricane, or other strong winds occur frequently. Taking Runyang Yangtze River Bridge (RYRB) as a research object, the contents and functions of WSHMS implemented on RYRB are introduced in detail. The sensory subsystem and the core functions of WSHMS are specifically illustrated. Thereinto, the core functions contain the finite element (FE) model updating, structural condition identification, and structural condition assessment. The research and establishment of WSHMS for RYRB can provide references for the structural health monitoring of other cable-supported bridges located at the similar geographical regions and environment.

\section{Engineering Background}

2.1. Descriptions of $R Y R B$. Located in the eastern area of China, RYRB is near the entrance of the Yangtze River to the Yellow Sea, as shown in Figure 1. According to the longitude and latitude, the bridge site belongs to the southeastern parts of the Asian continent. Taking account of the adaption of transportation to the development of economy, a super-huge and complicated engineering (RYRB) is put into construction in October, 2000. After nearly five years' harsh construction, RYRB was finally completed and open to traffic in April, 2005.

RYRB is an important lifeline engineering which firstly establishes the highway connection between Yangzhou and Zhenjiang across the Yangtze River in Jiangsu Province of China. It consists of two super-long-span cable-supported bridges, namely, Runyang Suspension Bridge (RSB) and Runyang Cable-stayed Bridge (RCB), as shown in Figure 2. RSB is a single-span hinged and simply supported steel-boxgirder suspension bridge with a main span of $1490 \mathrm{~m}$. When it was open to traffic in 2005, RSB was the first longest suspension bridge in China and the third in the world. In addition, the central buckle is applied to increase the overall stiffness of RSB, which is for the first time used in the suspension bridge in China. RCB is a steel-box-girder cablestayed bridge with three spans $(176 \mathrm{~m}+406 \mathrm{~m}+176 \mathrm{~m})$, double main towers, and double cable planes. 


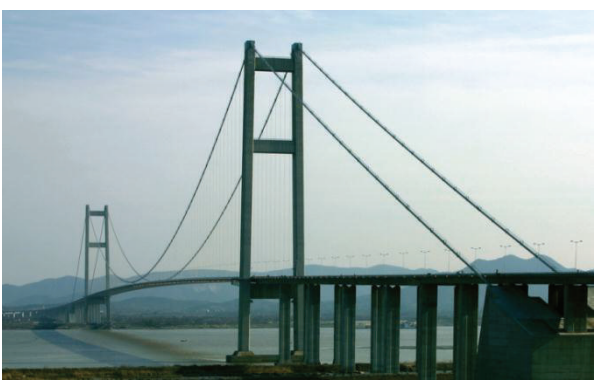

(1) RSB

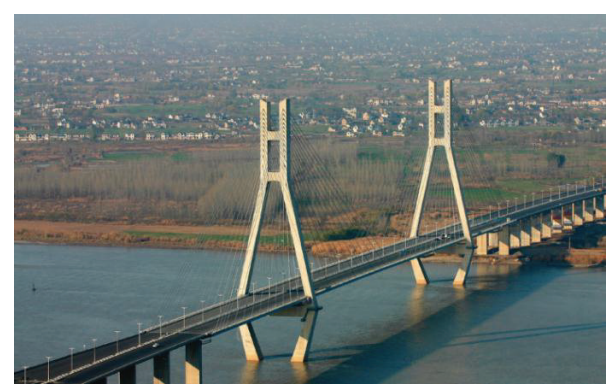

(2) RCB

FIgURe 2: View of Runyang Yangtze River Bridge (RYRB).

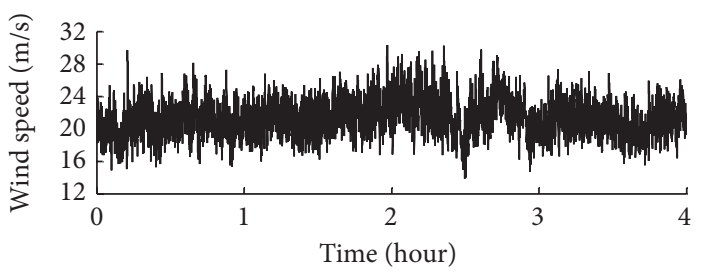

(a) Sample of Typhoon Haikui (2012-8-8T12:00-2012-88T16:00)

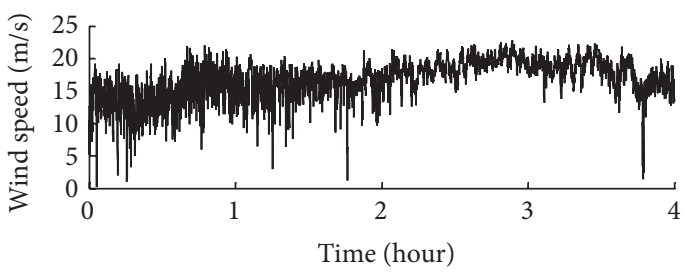

(b) Sample of strong north wind (2009-12-03T00:00-2009-1203T04:00)

FIGURE 3: Typical wind samples from WSHMS on RYRB.

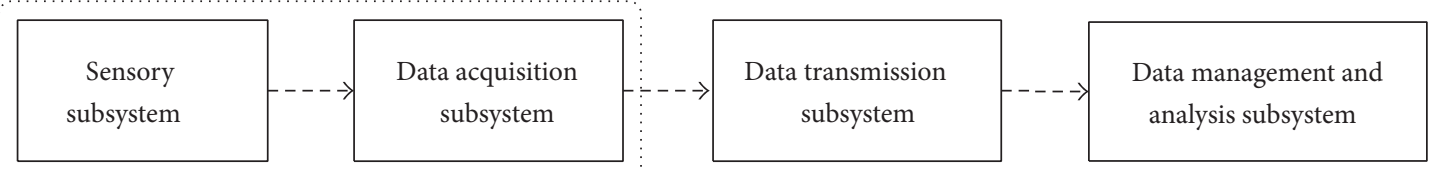

Data measurement system

FIGURE 4: The structure of WSHMS of RYRB.

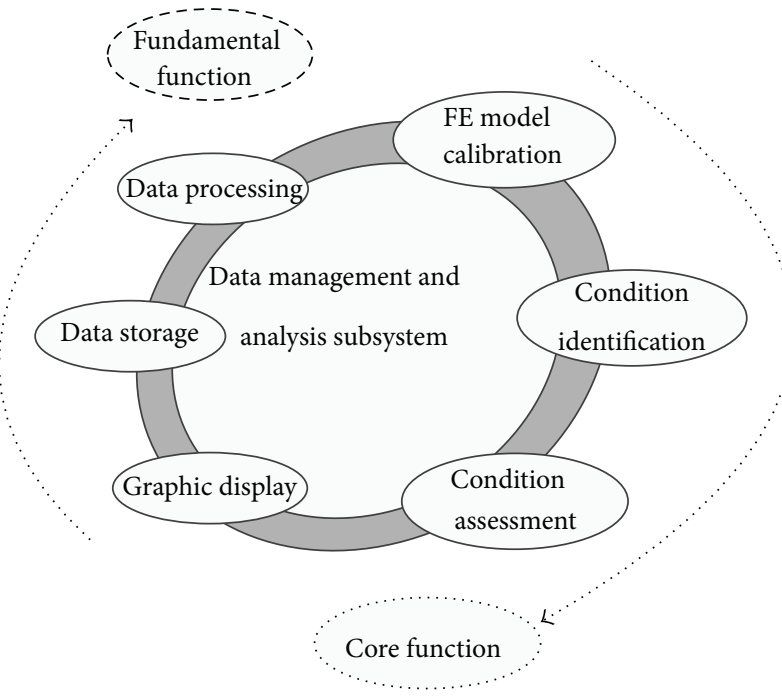

Figure 5: Structure of the functions of data management and analysis subsystem.

2.2. Wind Climate at the Bridge Site. The RYRB site belongs to the mid-latitude zone. According to the meteorological survey, the bridge site is dominated by the humid southern subtropical monsoon climate. Monsoon circulation has a significant influence on the seasonal changes of local weather patterns of RYRB site. The monsoon circulation usually leads to obvious seasonal climate, especially typhoon climate from eastern ocean in summer and the north wind from Siberia in the northwest of China in winter. Considering the performance of flexible structures in a strong wind environment, the wind-resistant stability of RYRB needs to be paid intensive attention to during typhoons and strong winds. As a typical example, Figure 3 shows the recorded wind samples of Typhoon Haikui in 2012 and strong north wind in 2009 from the WSHMS on RYRB.

\section{The Structure and Function of WSHMS on RYRB}

The WSHMS of RYRB contains four subsystems including sensory subsystem, data acquisition subsystem, data transmission subsystem, and data management and analysis subsystem (DMAS), as can be seen in Figure 4.

The fundamental function of WSHMS on RYRB is realized by sensory subsystem, which contains various transducers to better understand the input loads and measure output structural responses. In order to realize the recording, 


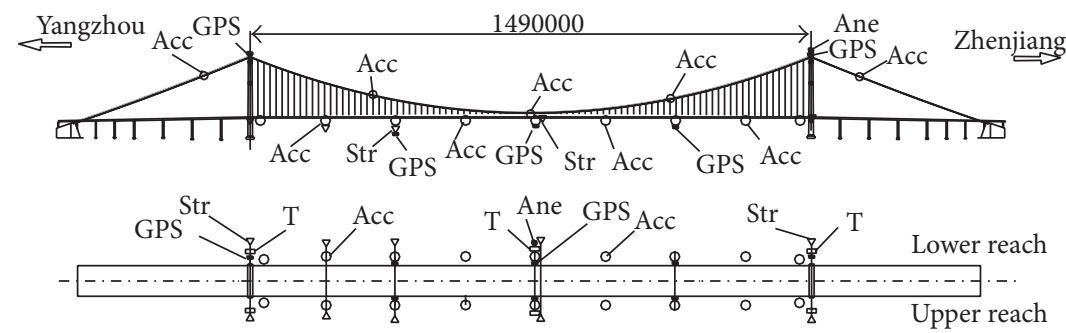

(1) Acc: accelerometer (85)

(3) Ane: anemometer (2)

(2) Str: stress gauge (72)

(5) GPS: GPS receiver (8)

(4) T: temperature sensor (28)

FIGURE 6: Layout of sensor system of RSB (dimension unit: mm).

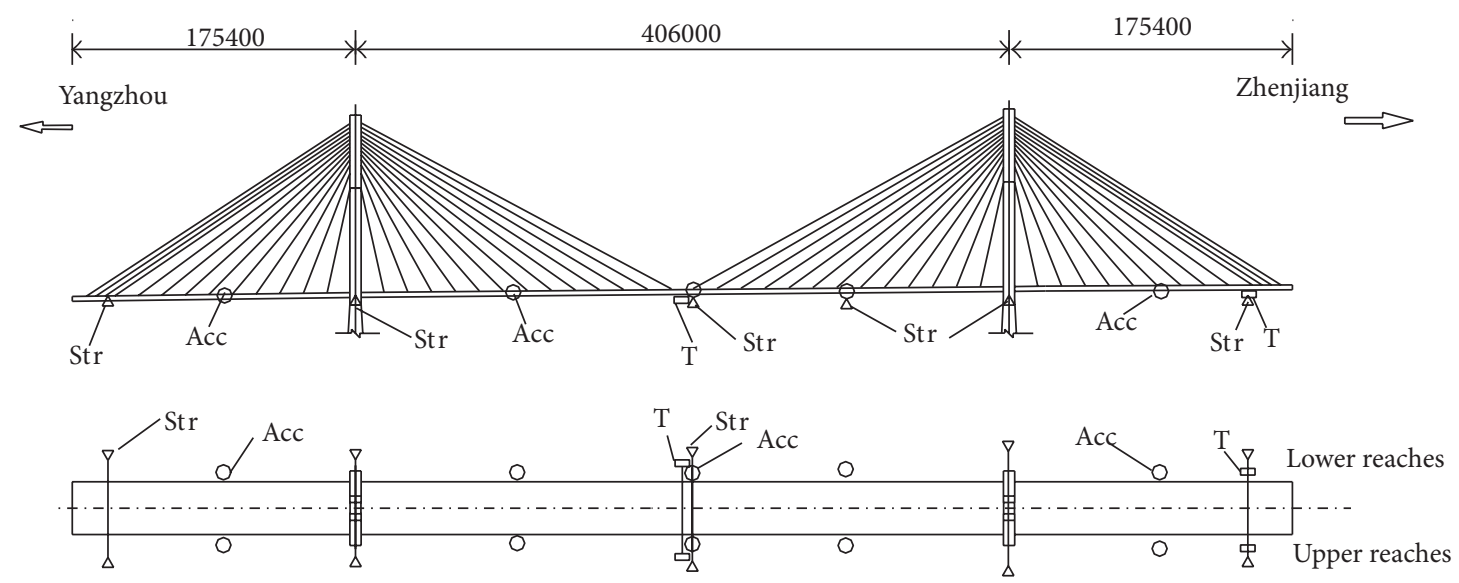

(1) Acc: accelerometer (15)

(3) T: temperature sensor (24)

(2) Str: strain gauge (94)

FIGURE 7: Layout of sensor system of RCB (dimension unit: mm).

transformation and quantification of multifarious signal sources, data acquisition subsystem has the functions to collect measured data from sensory subsystem and conduct adjustment and conversion of digital signals. The measured data will be transmitted to DMAS via data transmission subsystem, which is constituted by web server, optical switch, monitoring workstation, and optical fiber network.

As the most important part of the WSHMS on RYRB, the functions of DMAS contain the data processing and storage, graphic display of detected signals, progressive FE model updating, condition identification, and condition assessment based on the acquired data. The first three functions are composed of the fundamental function of DMAS, while the others perform as the core function for structural health assessment and decision making. The detailed function structure of DMAS can be seen in Figure 5.

\section{Sensory Subsystem of WSHMS on RYRB}

The WSHMS is a technique which can provide structural health conditions for decision making. Based on the WSHMS, the bridge supervisors can reasonably draw up plans for bridge inspection and maintenance. The main contents and sensors layout of the WSHMS on RYRB are determined mainly by the structural static and dynamic analyses, the importance and durability of structural components, the structural characteristics, the requirements of the system functions, and construction expenditure. Figures 6 and 7 show the sensor layout of RSB and RCB, respectively. The number in the bracket represents the quantity of sensors.

\subsection{Sensors Layout of RSB}

4.1.1. Main Cable and Suspender Monitoring. The main cable is one of the most important components related to the safety operation of a suspension bridge. Therefore, 32 accelerometers were installed at 4 anchor rooms ( 8 accelerometers in each anchor room) to monitor the vibrations and frequencies of the typical cables, and likewise the forces of the cables can be achieved based on the relation between the cable tension and the vibration frequency. The vertical and lateral vibration responses of the main cable were monitored by 12 low-frequency single-axis accelerometers, as shown in Figure 8. Considering the large quantity of the suspenders, the suspenders of RSB were periodically tested 


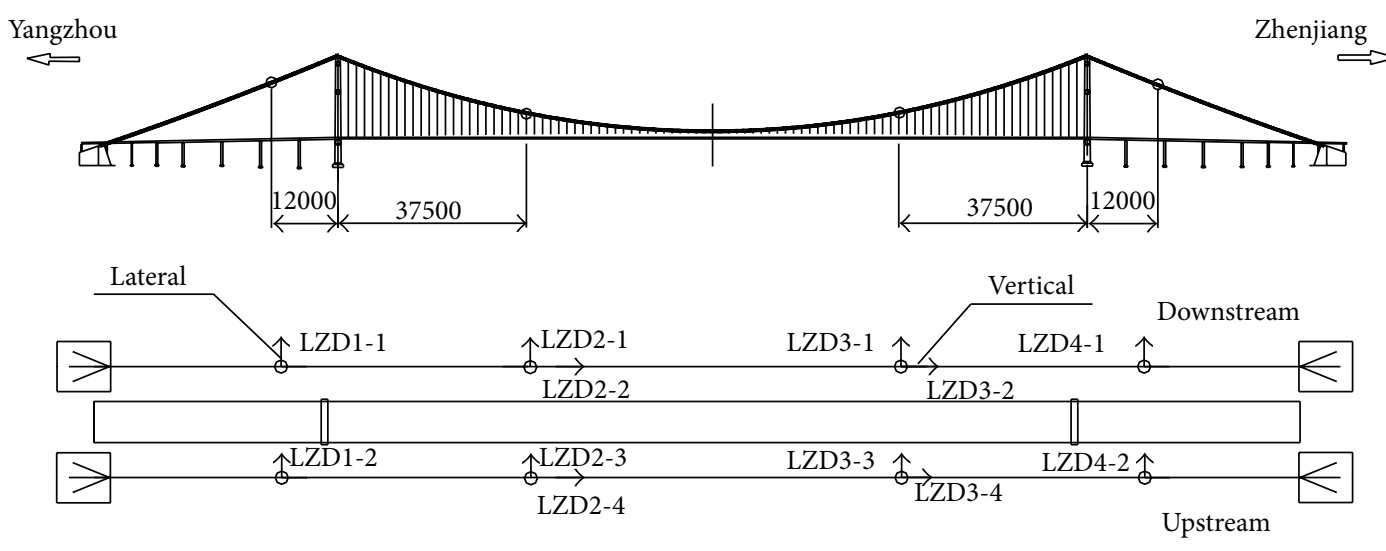

Figure 8: Layout of anemometers on the main cable of RSB.

with additional field tests and the measurement results are brought into the whole structural assessment system.

4.1.2. Main Girder Monitoring. Considering both of the structural characteristics of the main girder, the girder monitoring mainly focuses on the overall line type, stress, temperature, and vibration. The Global Positioning System (GPS) is demonstrated with an ability to accurately extract static and quasistatic displacements of the bridge induced by ambient effects [12-15]; thus 6 GPS measuring points are settled at 3 quartered sections to monitor the line type of the main girder, as shown in Figure 6. The monitoring station is set up near the GPS bench marks of China. In order to monitor the longitudinal displacement, 4 linear displacement sensors are installed at two ends of the girder (two in each end). Considering the optimization results of genetic algorithm and the requirements of real-time modal analysis, 29 low-frequency single-axis accelerometers are installed at 9 sections of the girder to monitor the vibration responses.

Considering many factors such as structural deformation and stress layout under static loads, symmetry of the structure, special design of the central buckle, and optimization analysis with the genetic algorithm, 72 strain gauges including fiber sensors, vibrational chord strain gauges, and welding strain gauges are installed at 5 sections of the main girder to monitor the structural stress status. Since the temperature has a significant effect on the fatigue property of welding steel box girder [16], 28 temperature sensors were installed at 3 sections of the main girder to monitor the temperature distribution and changes. Thereinto, 12 temperature sensors are installed on the $L / 2$ ( $L$ is the span of the RSB) section of RSB and 8 temperature sensors are installed on the side section individually.

4.1.3. Main Tower Monitoring. The main tower is the most important element of a suspension bridge. In order to monitor the vibration response of the two towers, 6 accelerometers are uniformly installed at the upper crossing girder and the mid crossing girder of each tower, which is detailed in Figure 9. In addition, 2 GPS measuring points are settled at

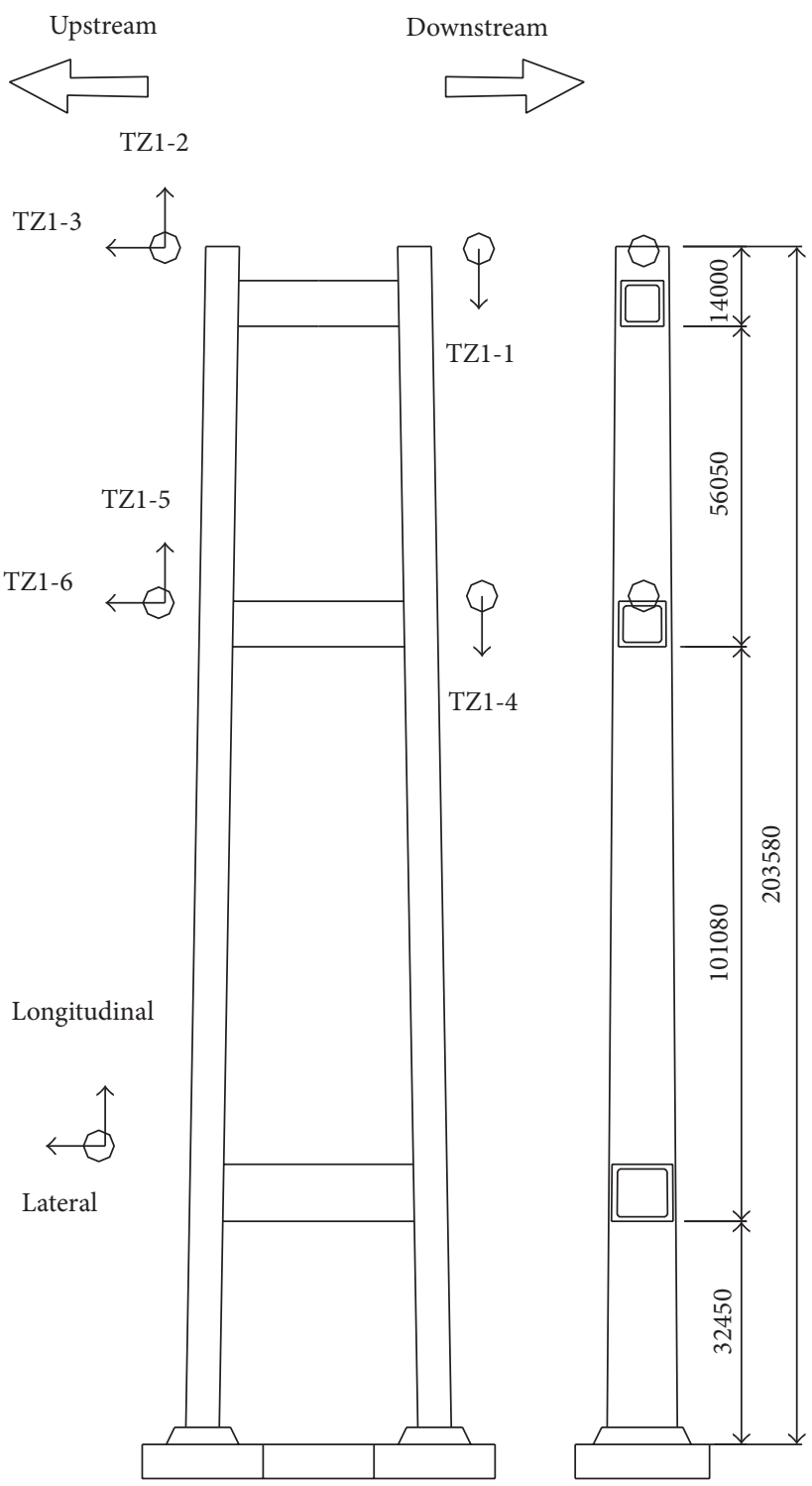

FIGURE 9: Layout of the accelerometers on the main tower of RSB (dimension unit: $\mathrm{mm}$ ). 


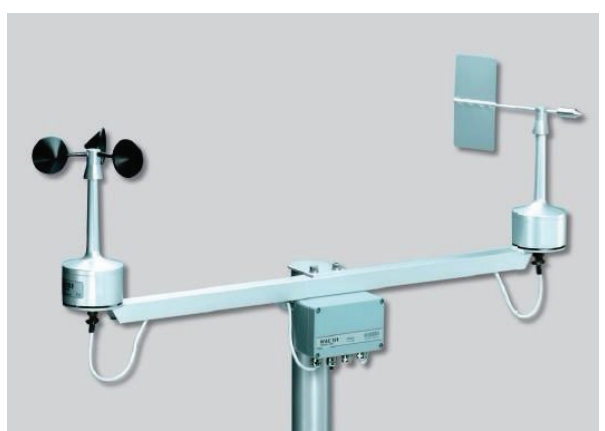

(a) WA15

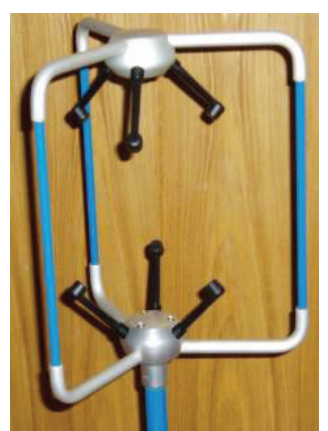

(b) $1590-\mathrm{PK}-020$

FIgURE 10: Anemometers installed on RSB.

the top of the two towers to monitor the displacements of the towers.

4.1.4. Wind Environment Monitoring. Considering the typical wind environment at the bridge site, two kinds of anemometers are installed on RSB to monitor the wind velocity and wind direction: the WA15 anemometer from the Vaisala Company (Finland) and the 1590-PK-020 3D ultrasonic anemometer from the Gill Instruments Limited (England). Two WA15 anemometers are used in the WSHMS of the RSB (Figure 10(a)), and three 1590-PK-020 3D ultrasonic anemometers are installed only during strong winds (Figure 10(b)). All the anemometers can be utilized to analyze the wind effects acting on RSB [17]. One of the WA15 anemometers is deployed on the top of the south tower (downstream) and the other in the middle of the main span (downstream). North wind is defined as $0^{\circ}$ for anemometers data, and clockwise rotation is defined as the positive direction. Long-term successful applications in meteorological studies have shown that the WA15 anemometers can work effectively under all kinds of bad weather and acquire accurate information about wind environment.

The WA15 anemometers in WSHMS collect time history of wind speed and direction with the frequency of $1 \mathrm{~Hz}$, so it can only provide average or maximum data about wind speed and direction. Because of this limitation, three 1590-PK-020 $3 \mathrm{D}$ ultrasonic anemometers are used in the field test during the strong winds. The 1590-PK-020 anemometer has light weight and small volume. The maximum sampling frequency can reach $32 \mathrm{~Hz}$. Owing to the above features, it is used widely in the wind testing of engineering structures. These three anemometers can be installed in other key positions of the RSB during strong wind periods, so that the wind environment characteristics of strong winds can be measured more accurately and comprehensively.

4.1.5. Traffic Loads Monitoring. Due to the low precision and high price of current vehicle load and vehicle velocity dynamic measurement system, the system was not applied in the WSHMS of RSB. Based on the data provided by the traffic system, the vehicle loads and vehicle velocities on RSB were determined mainly by the traffic loads model, which is built by use of the statistical method.

\subsection{Sensors Layout of $R C B$}

4.2.1. Cable Monitoring. The stay cable is one of the most important components in a cable-stayed bridge and its working performance is closely related to the health status of the overall structure. Therefore, the distribution and fluctuation of cable forces must be acquired accurately in order to analyze the working condition of the cables and determine the cable forces in FE model accordingly. Like the suspenders of RSB, the cable monitoring of RCB is complemented with additional periodical field tests, and then the measurements will be integrated into the WSHMS afterwards.

4.2.2. Main Girder Monitoring. The main girder monitoring of RCB mainly contains the monitoring of stress distribution, vibration status, and temperature distribution and fluctuation. As shown in Figure 7, 15 low-frequency accelerometers are installed at 5 sections of the main girder to monitor the vertical and lateral vibration responses. 94 strain gauges including fiber sensors, vibrational chord strain gauges, and welding strain gauges are installed at 5 key sections to monitor the stress distribution on the steel box girder. Considering the symmetry of RCB, 24 temperature sensors are installed at 2 sections ( $L / 2$ section and side section near Zhenjiang) of the main girder to monitor the temperature distribution and fluctuation all year round.

\section{Progressive Finite Element Model Updating of RYRB}

An accurate and reliable FE model is essential for the studies on wind resistance, structural health monitoring, and condition assessment [18]. Therefore, establishing a baseline FE model is the research basis for any kind of numerical analysis. Many FE model updating techniques have been proposed based on measured data in order to achieve an FE baseline model suitable for the analysis object. In most of the model updating approaches, the FE baseline model of the structure is obtained by reducing the error between the measured structural response and the calculated response from a numerical model. During the model updating procedure, the corresponding design parameters should be updated simultaneously. Obviously, too many design parameters may 


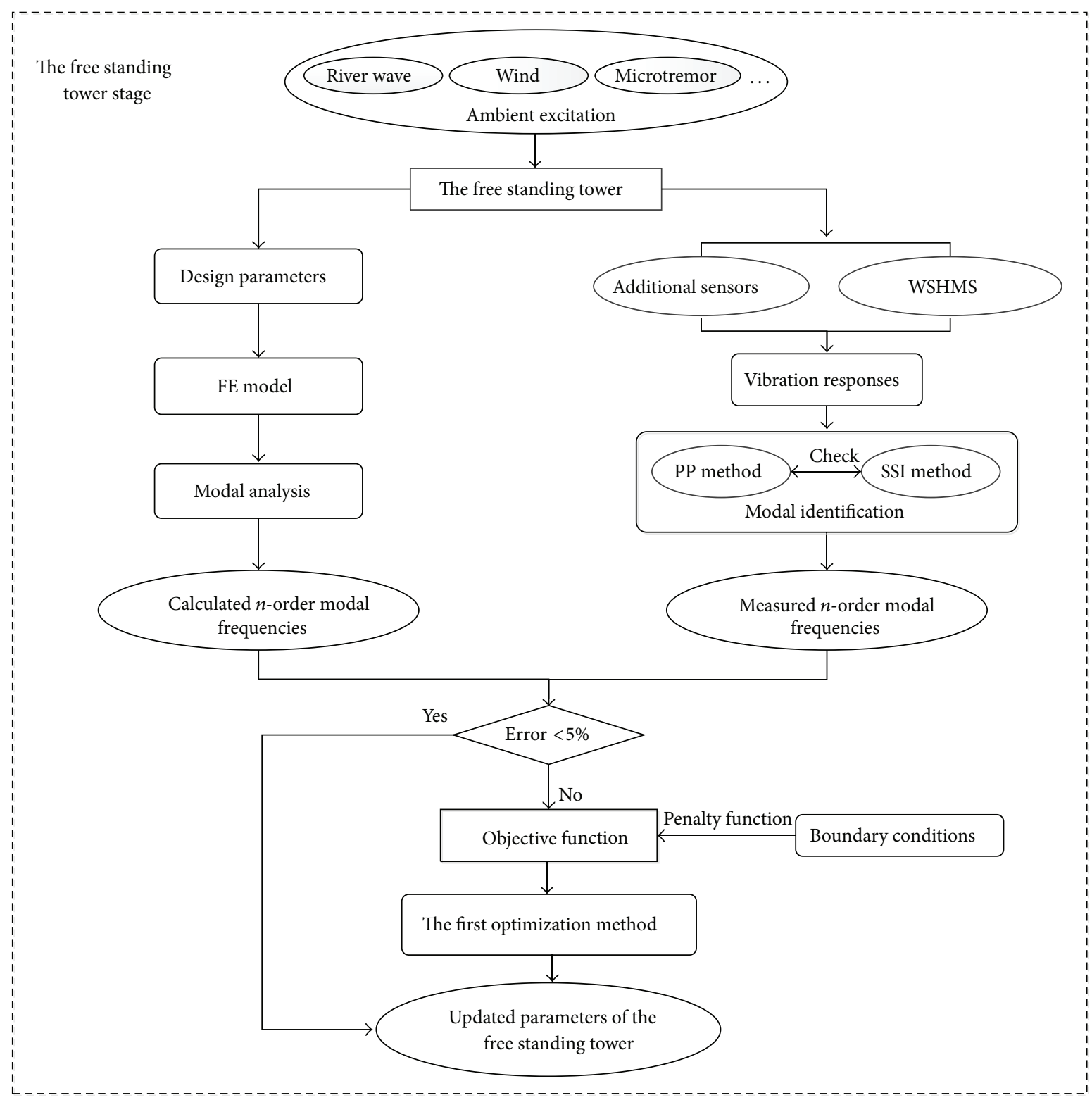

FIGURE 11: FE model updating of the free standing tower stage.

decrease the updating efficiency and increase the complexity of model updating. However, a more accurate FE model will be acquired when taking more input parameters into account. Hence, a tradeoff between the complicity of the optimization and the accuracy of the numerical model has to be made.

Being aware of the aforementioned limitations of model updating technique, a three-stage model updating strategy is proposed for the application in the progressive FE model updating of RYRB. Among the three-stage model updating strategy, the first two stages will provide an initial baseline FE model for the operation stage [18].

5.1. The Free Standing Tower Stage. When the main tower of RYRB is completed, a field test is conducted to examine the structural status. The accelerometers in WSHMS and the additional sensors can record its vibration responses from ambient excitation, such as river waves, wind, and ground microtremor. Based on the measured structural vibration responses, the structural modal parameters are identified by the peak picking (PP) method. The identification results are then validated and complemented by the stochastic subspace identification (SSI) method. Considering the importance of low order modes, the first $n$ modal frequencies are taken into the model updating process. Other acquired modal frequencies will be used to validate the updated FE model afterwards.

With the initial structural parameters, a FE model of the free standing tower can be established. The cross-section area, moment of inertia, material density, and elastic modulus are taken as the updating parameters based on the parameter sensitivity analysis. The first $n$ modal frequencies of the tower can be calculated by modal analysis, and the error 


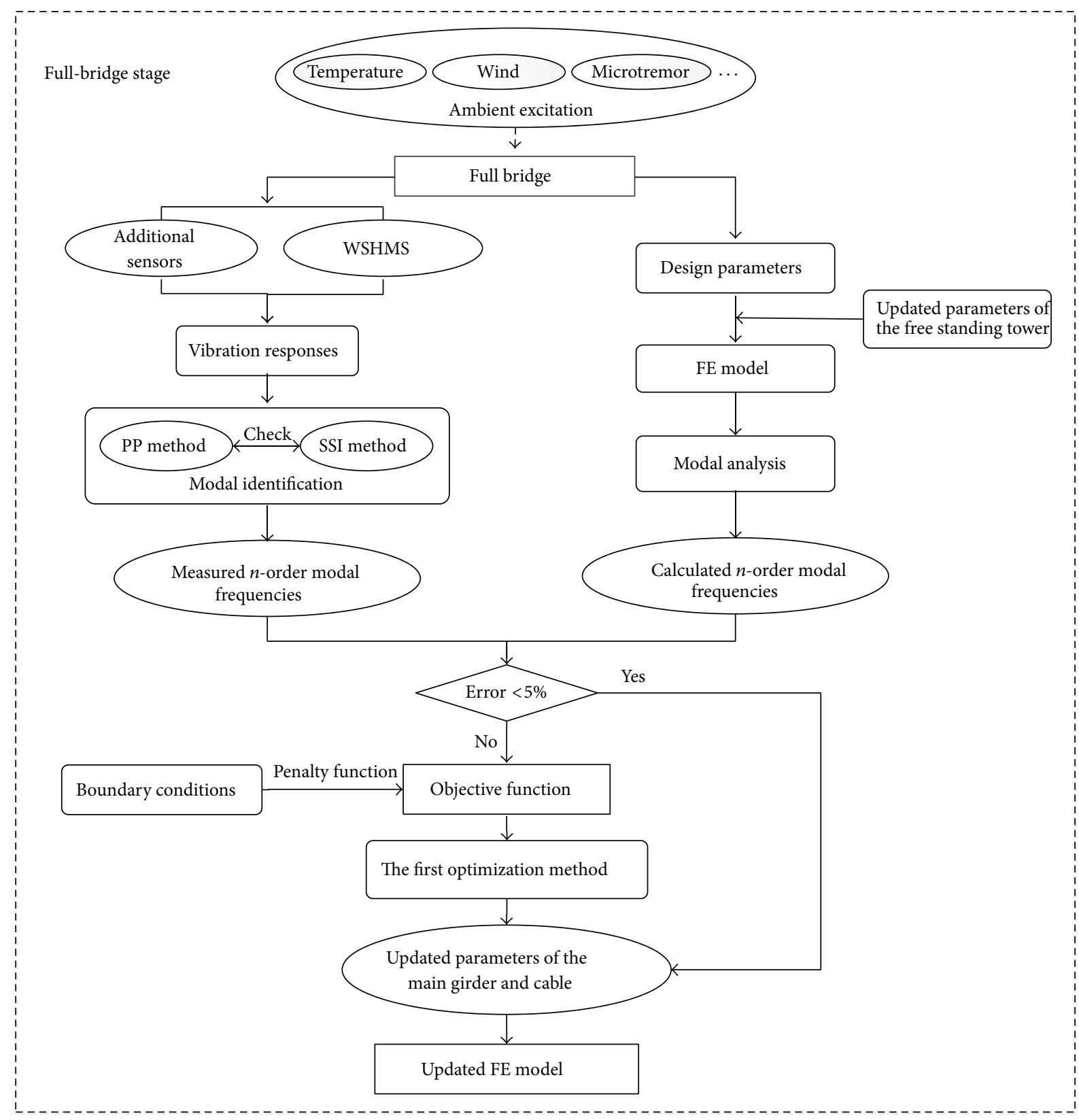

FIGURE 12: FE model updating of full-bridge stage.

between each corresponding calculated and measured modal frequency is defined as a state variable, specified as

$$
\text { Error }=\frac{\left|f_{c}-f_{m}\right|}{f_{m}},
$$

where $f_{c}$ is the calculated modal frequency and $f_{m}$ is the measured modal frequency.

If each error between calculated and measured modal frequency is below the acceptable level 5\%, the structural parameters would be permitted for the updated FE model; otherwise a parameter optimization procedure will be carried out. In the procedure, the model updating problem is transformed into a multiobjective nonlinear optimization problem under constraints of equality and inequality. An objective function is proposed as the sum of the square of errors between the calculated and measured frequencies multiplied by corresponding weighing factors, detailed as

$$
\begin{gathered}
J=\sum_{i=1}^{n} \varphi_{i} E_{i}^{2} \quad(i=1,2, \ldots, n), \\
\varphi_{i}=\frac{E_{i}^{2}}{\sum_{i=1}^{n} E_{i}^{2}} \quad(i=1,2, \ldots, n),
\end{gathered}
$$

where $J$ is the objective function; $\varphi_{i}$ is the weighing factor; $E_{i}$ is the error between calculated and measured value of the $i$ th modal frequency. Taking the boundary conditions into 


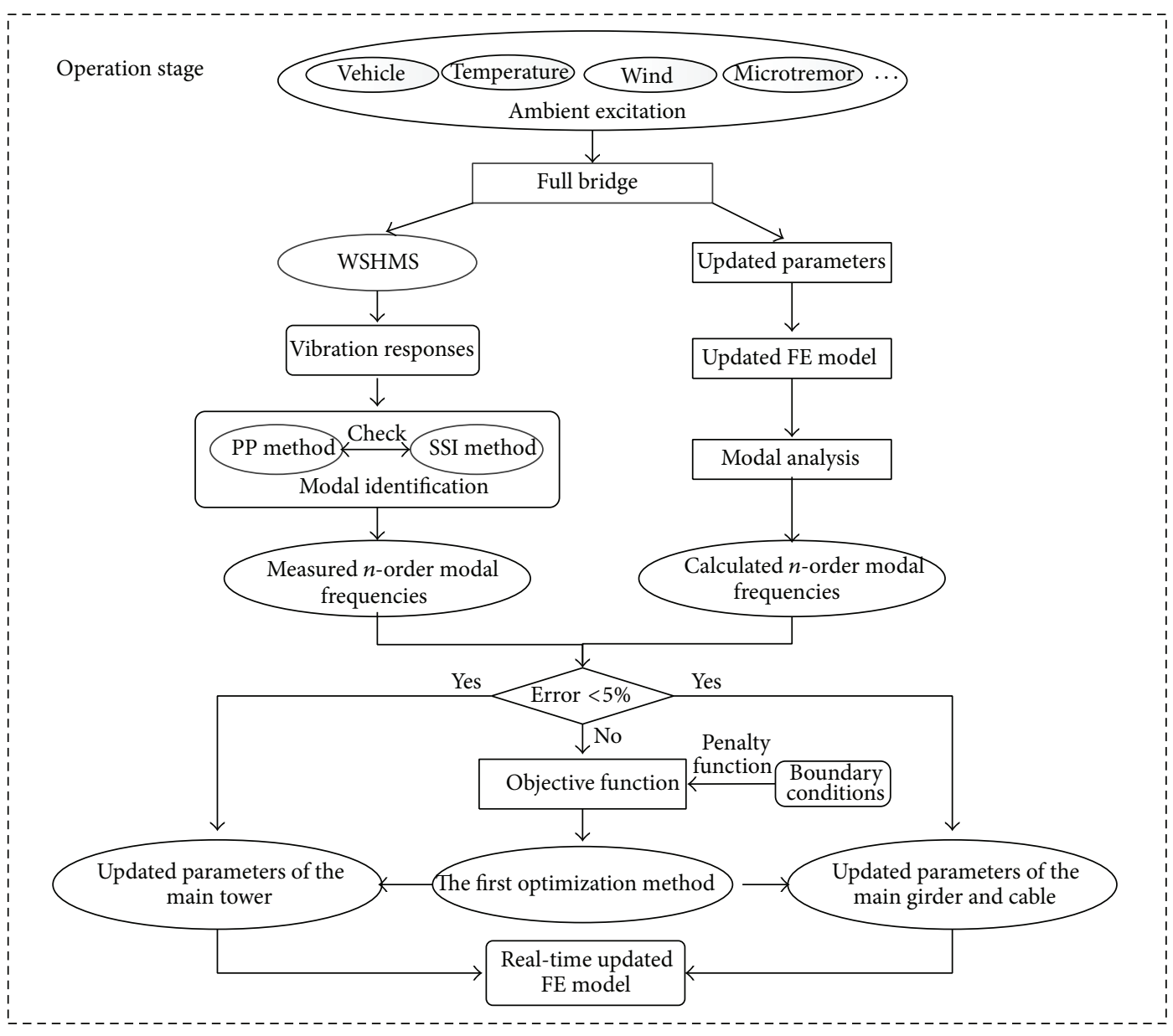

FIGURE 13: FE model updating of the operation stage.

the objective function with penalty function, the updated structural parameters of the free standing tower can be acquired by the first optimization method [18]. The detailed calibration process can be seen in Figure 11.

5.2. Full-Bridge Stage. In the second stage, structural parameters of the steel girder and the main cable will be updated after the construction of RYRB is finished. The model updating procedure is similar to that of the free standing tower. Based on the parameter sensitivity analysis, the selected updating parameters contain the material density, elastic modulus, and moment of inertia of the steel girder as well as the material density and elastic modulus of the main cable. In the establishment of the FE model of full bridge, the updated structural parameters of the free standing tower are employed and they are kept constant during the calibration procedure. In the stage, the first $n$ modes contain vertical bending, lateral bending, and torsional modes of the main girder as well as the longitudinal bending, lateral bending, and torsional modes of the main tower. After the process in Figure 12, the updated parameters of the main girder and cable can be obtained, and an initial FE model with the updated parameters of the full bridge will be finally established.
Before RYRB was open to the traffic, a field load test is conducted and the corresponding static responses can be accurately recorded by WSHMS. Taking the same loading scheme, the structural deformation and stress distribution under the static and dynamic loads can be calculated with the FE model. The measured structural responses during the field load test can be employed to validate the reliability of the acquired FE model, so that an initial baseline FE model can be provided to the operation stage.

5.3. Operation Stage. Compared to construction stage, RYRB suffers from additional vehicle actions and continuous environmental loads in its long service period. Hence, the performance deterioration and partial damage will inevitably occur in some structural components, which may cause the variation of structural dynamic characteristics. A realtime FE model which can reflect the structural material and performance deterioration really needs to be established for structural condition assessment. To make the FE model accurate and reliable during its whole life cycle, the real-time recorded data from WSHMS are employed for validating the real-time updated FE model. Similar to construction stage, the FE model updating of RYRB in operation stage is shown in Figure 13. 


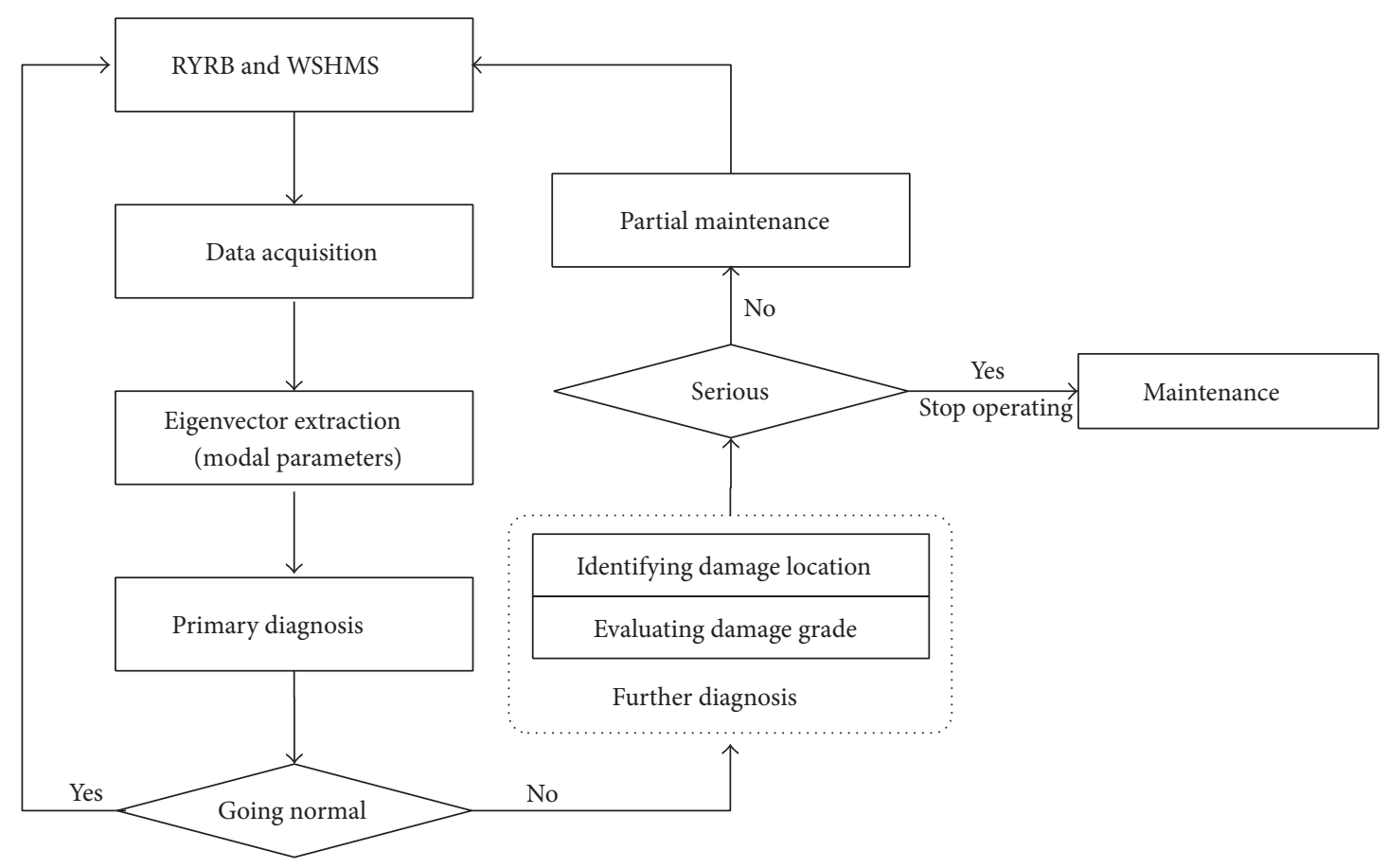

FIGURE 14: Condition identification strategy of RYRB.

\section{Condition Identification of RYRB}

One of the most important objectives of the WSHMS is to diagnose the damage and health condition of structures during service period. Large quantities of real-time data can be acquired from the WSHMS, which makes the existing problem for structural condition identification is how to convert the structural responses into the structural health information. Condition identification theory or method is just the way to diagnose structural abnormal state or damage. Many researches on structural condition identification using the field tests have been conducted, and the efficiency of structural condition identification based on static and dynamic responses has been validated by experiments [1923].

The structural condition identification strategy in WSHMS of RYRB is shown in Figure 14. Based on the WSHMS, the structural responses will be recorded and transmitted to DMAS [24]. Some eigenvectors which can describe structural damage status will be extracted from the acquired data. Hereinto, modal parameters including mode frequencies, mode shapes, and damping ratios are selected as the eigenvectors. Furthermore, the modal assurance criteria (MAC) are adopted as the damage indicator to increase the sensitivity of modal parameters to structural damage. The structural condition identification is classified into two ordinal phases; one is primary diagnosis with statistical analysis technique and the other is further diagnosis with neural network. The primary phase only briefly distinguishes whether the modal parameters are abnormal or not, while the further phase will determine the damage location and evaluate the damage grade. Finally, whether a practical

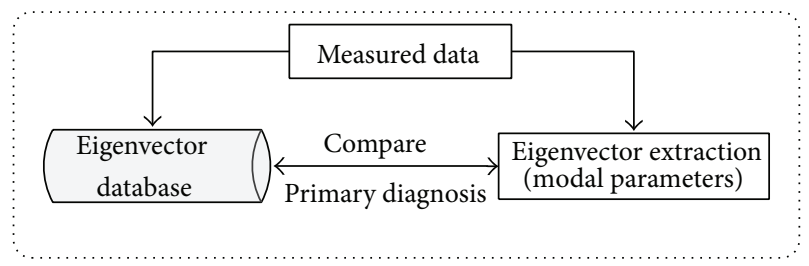

Figure 15: Primary damage diagnosis of RYRB.

maintenance is needed would be determined by the structural damage degree.

6.1. Primary Diagnosis Based on Statistical Analysis Technique. The efficiency of primary diagnosis relies on two factors, the extracted eigenvectors and the eigenvector database. Since the completion of RYRB, modal parameters of normally operated structure have been gradually accumulated from WSHMS. And an eigenvector database is set up with the statistical analysis result of accumulated modal parameters. Therefore, the primary diagnosis will depend on the comparison between the real-time extracted modal parameters and the eigenvector database. The primary diagnosis process can be seen in Figure 15.

6.2. Further Diagnosis Based on Neural Network. Due to the large scale of engineering structure and the randomness of influence factor, it is difficult to accurately acquire all the effective data related to local damage. Hence, many condition identification methods lose their own efficacies. But neural network accompanied by genetic algorithm can effectively 


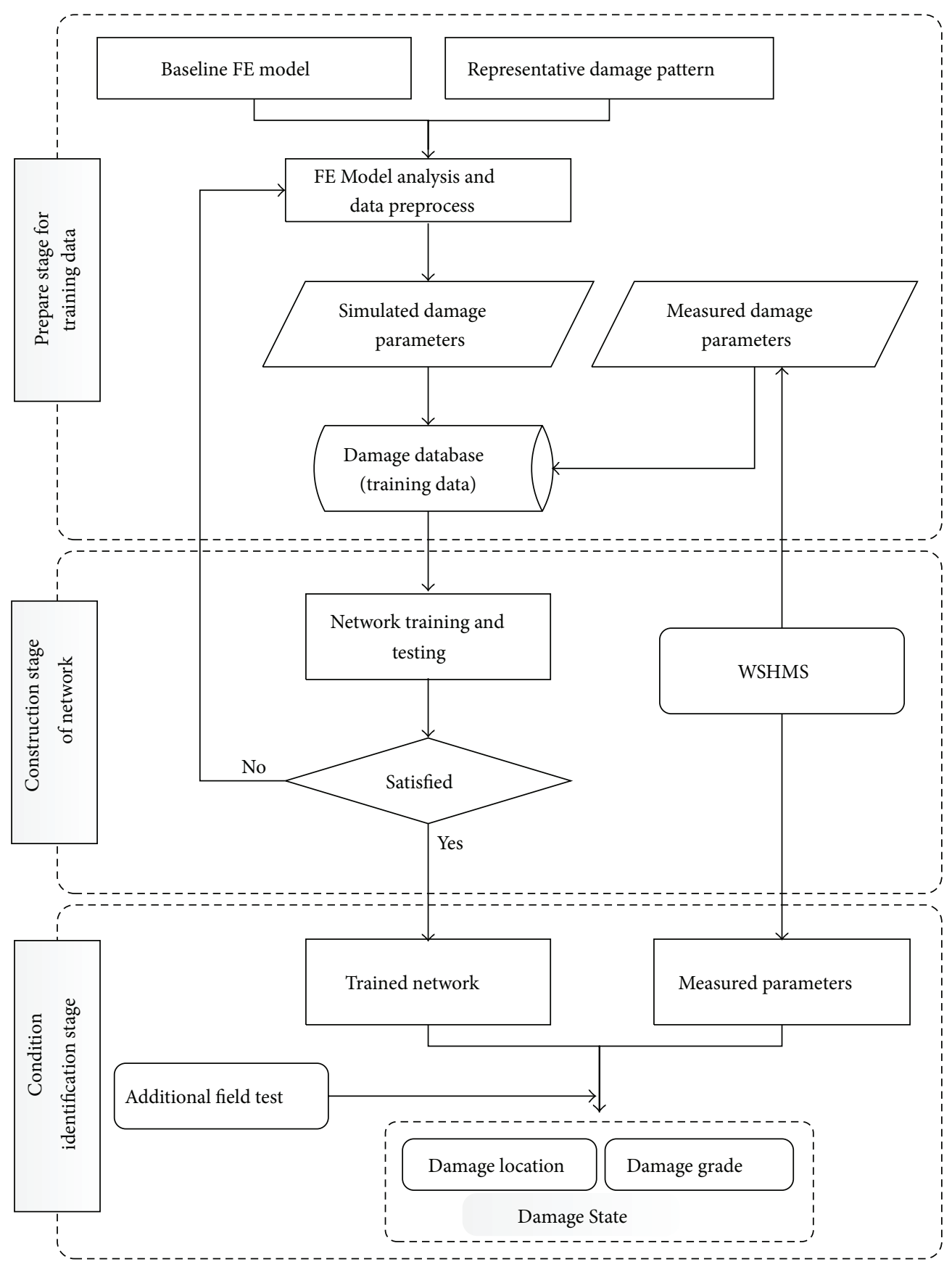

FIGURE 16: Further damage diagnosis based on neural networks.

explain the variation of structural state no matter from intuitive thinking or from uncertain reasoning on account of its strong fault tolerance, robustness, and generalization ability. Meanwhile, the development of computer techniques makes the computational efficiency rapidly increased, which makes it feasible to diagnose the health status of engineering structures.

In the further condition identification of RYRB, BP neural network is utilized to reflect the relationship between structural damage pattern and its characteristics and further identify the damage location combined with the analyses of structural damage status. The further damage diagnosis of RYRB is divided into three stages, as shown in Figure 16.

The first stage aims to prepare training data for the neural network with the combination of FE analyses and field measurements. With the real-time baseline FE model provided by the model updating and representative damage patterns, the structural parameters embodying partially damage can be well simulated. Based on the measured parameters from the WSHMS, a damage database which stores the training data for neural network would be established. During the second stage, the topological structure of BP neural network 


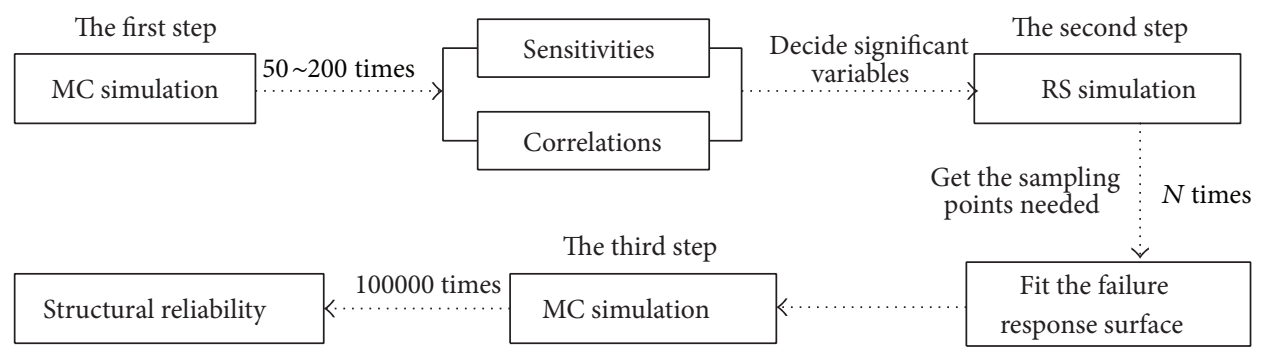

FIgURE 17: The flow chart of the combined simulation method.

is constructed and the network is trained with the sample set from the damage database. If the trained network satisfies with the accuracy requirement, it can be employed to serve for the third stage. The third stage is to assess the damage state of RYRB. Structural damage location and grade can be achieved by inputting the measured modal parameters into the trained BP neural network model. In order to accurately and reliably recognize the real structural damage state including damage location and damage grade, some additional field tests should be conducted near the possible damage locations.

\section{Condition Assessment of RYRB}

Safe and reliable operation of bridges has become a major concentration of both civil engineers and the government. However, whether current technologies and operational procedures can ensure the necessary serviceability, the costeffective maintenance and management of bridges still lack an explicit evaluating criterion. These limitations in current practice can be overcome by emerging concepts and tools for accurate condition assessment of civil infrastructures [25]. Conventional bridge condition assessment is generally conducted with measured data from visual inspection, which has been proved to be limited and subjective. The development of structural health monitoring provides a new valuable practice into structural condition assessment. With plentiful data acquired from the SHMS, the condition of inservice bridge structures and insights into actual behavior of bridges under in-service environment can be well recognized based on reliability condition assessment methods [26, 27]. Considering integral security and the fatigue characteristic of steel material, the condition assessment of RYRB is composed of structural reliability assessment and structural fatigue assessment [24].

7.1. Structural Reliability Assessment. In the structural reliability assessment of RYRB, the core part is a combined numerical simulation method which has the advantages of the Monte Carlo (MC) method and the response surface (RS) method. The main procedure can be seen in Figure 17.

The combined method mainly contains the following steps. Firstly, the MC method is used to compute the probabilistic sensitivities and the correlations between random variables (input variables) with 50 200 times of samplings. In this way, the variables that have more significant effect on the output index can be determined according to probabilistic sensitivity analysis. The comparatively important input variables will be kept for following process while the others will be omitted. Then the failure response surface of different output variables can be fitted through RS simulation. Finally, the MC method (100,000 times of samplings) will be used again to get the structural probability of each main failure mode based on this response surface.

Combined with monitored data from WSHMS, the detailed reliability assessment of RYRB is shown in Figure 18. The whole procedure is mainly divided into three specific parts. In the input module, the environment information and vehicle loads will be processed with statistical method, so that the statistical value of external actions can be input to the evaluating model afterwards. If some structural damage has occurred and been examined by the monitoring system, the damage information can be delivered to the evaluating model as well. In the simulation module, the combined simulation method aforementioned and the updated FE model will be utilized to calculate the reliability of each main failure mode. In the output module, the max stress of girder, cable, and central buckle, the max vertical and horizontal displacements of girder, and the max horizontal displacements of the tower will be displayed. The reliability of the member with extreme responses will be evaluated and the serial number of the perilous member will be recorded with a label. According to the probability index, the structural reliability state and the suggested maintenance action can be given.

7.2. Structural Fatigue Assessment. Fatigue is a prominent problem that exists in steel structures $[28,29]$. If the stress fluctuates obviously, stress far less than yield strength can cause the failure of steel members. In the fabrication of steel structures, welding is one of the most frequently used approaches, but welded joints in steel structures are vulnerable to failure by fatigue for the inner flaws or discontinuities $[16,30]$. Considering the fatigue accumulation in welded joints of the steel box girder, the structural fatigue assessment of RYRB mainly focuses on the plentiful welded joints between each segment of the deck. The structural fatigue assessment can be seen in Figure 19.

Based on the online original data of strain acquired from WSHMS of RYRB, the recorded data in time domain can be transformed into statistical information at frequency domain with FFT technique. Using multiple linear regression method, a representative sample of strain time-history can be 


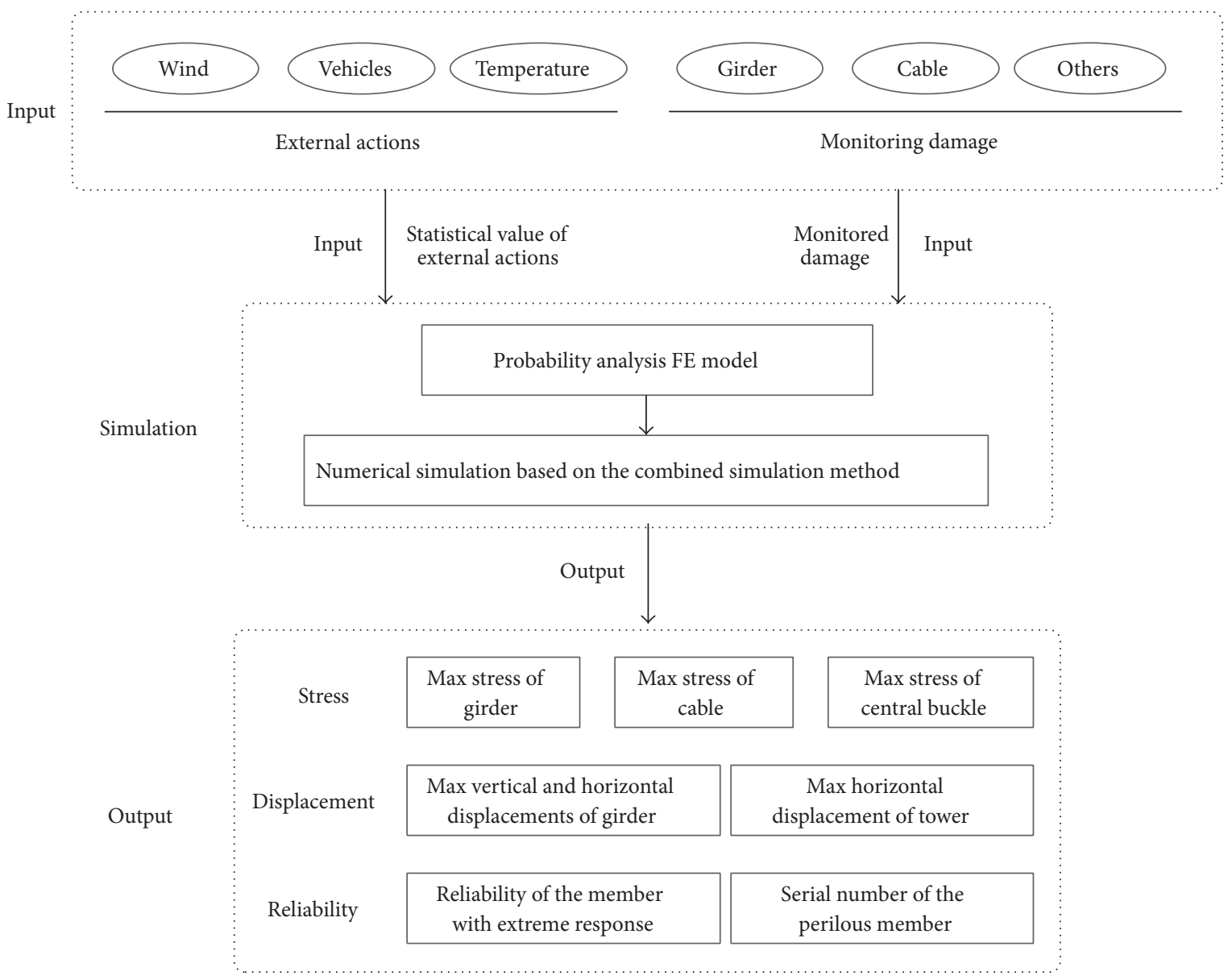

FIGURE 18: Reliability assessment of RYRB.

obtained. Then the rain-flow counting method is utilized to determine the stress spectrum of the representative sample. Since the measured stress is the nominal stress at the location of the gauge, it should be modified with coefficient to obtain the hot-spot stress at the toe of weld. The primary assessment of fatigue life is undertaken based on BS5400 [31] and a modified probability model is proposed as well. Combined with continuum damage mechanics (CDM) model and miner model, the reliability assessment of fatigue life on RYRB will be conducted comprehensively. Hence, the periodic inspection and maintenance scheme for RYRB can be formulated reasonably.

\section{Summary and Conclusion}

This paper introduces the establishment of a WSHMS for RYRB in China, and the composition and functions of the WSHMS are presented. The WSHMS of RYRB contains four subsystems including sensory subsystem, data acquisition subsystem, data transmission subsystem, and DMAS. Specifically, the sensory subsystem, which is utilized to measure the input actions and structural output responses, and the core functions of the DMAS including model updating, structural condition identification, and structural condition assessment are illustrated in detail.
A three-stage model updating strategy is proposed for the progressive FE model updating of RYRB. Thereinto, the measured structural static and dynamic responses are adopted to acquire the target benchmarks of RYRB and the first-order optimization method is used to enhance the computing rate of convergence. Among the proposed threestage model updating strategy, the first two stages can provide an initial baseline FE model for the operation stage, and the operation stage offers a real-time FE model for structural condition identification and assessment.

In the WSHMS of RYRB, a two-phase strategy is proposed to carry out the structural damage diagnosis and damage location identification. The primary diagnosis phase briefly distinguishes whether the measured parameters and responses are abnormal or not, while the further diagnosis phase will determine the damage location and evaluate the damage grade. On the basis of structural damage degree, whether a practical maintenance is needed or not can be decided.

Considering the integral security and the fatigue characteristic of steel structures, the condition assessment of RYRB is composed of structural reliability assessment and structural fatigue assessment. Structural reliability assessment serves with a combined numerical simulation method taking the advantages of both the Monte Carlo method and the response 


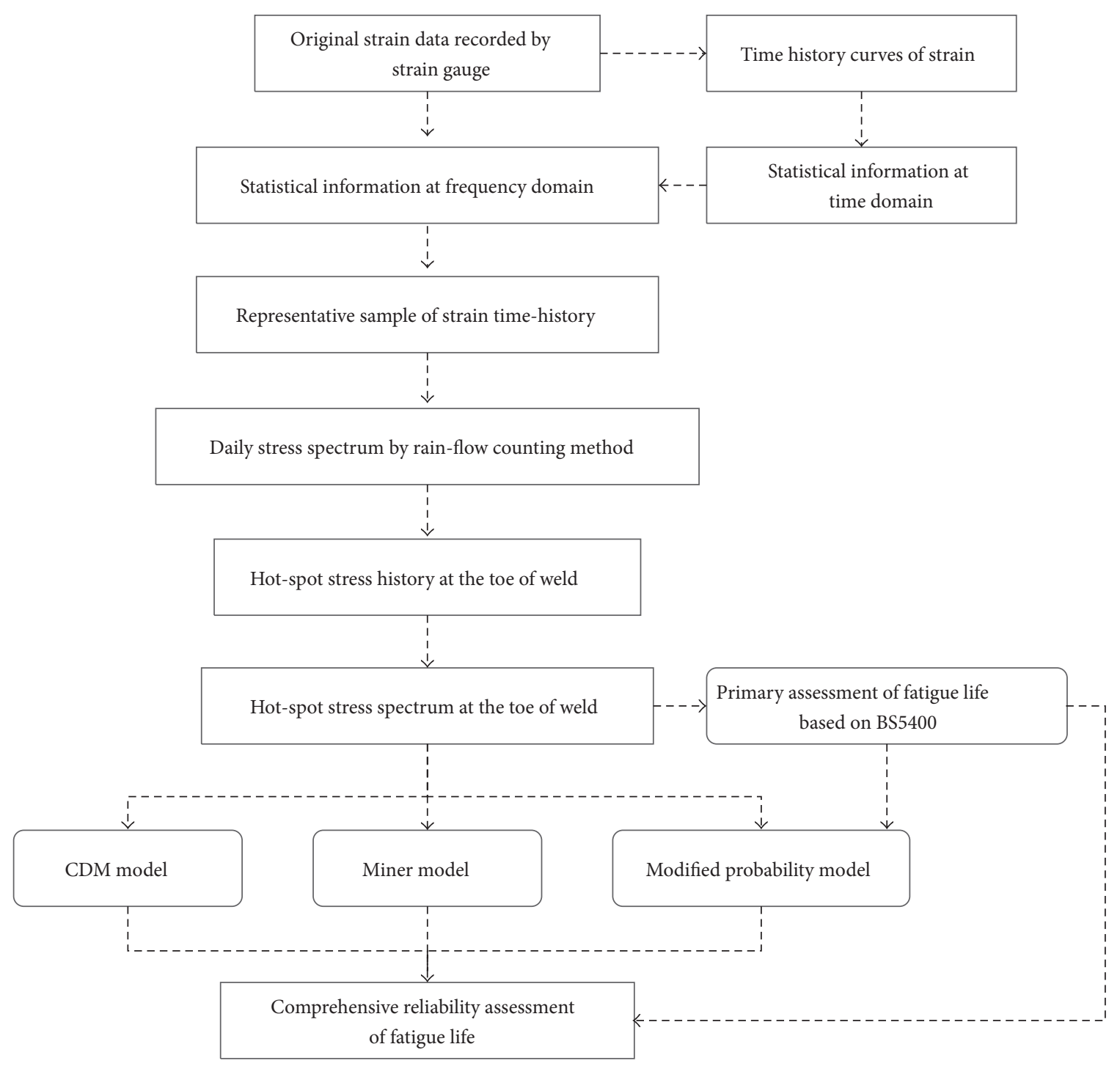

FIGURE 19: Structural fatigue assessment of RYRB.

surface method, while structural fatigue assessment is a comprehensive evaluation with empirical and modified model based on real-time measurements from WSHMS.

\section{Conflict of Interests}

The authors declare that there is no conflict of interests regarding the publication of this paper.

\section{Acknowledgment}

The supports from the National Science Foundation of China (Grant nos. 5137811land 51438002), the Major State Basic Research Development Program of China for Young Scientists (973 Program, Grant no. 2015CB060000), the Program for New Century Excellent Talents in University of Ministry of Education of China (Grant no. NCET-13-0128), the Fok Ying-Tong Education Foundation for Young Teachers in the Higher Education Institutions of China (Grant no.
142007), the Jiangsu Transportation Department (Grants nos. 2011Y09-2 and 2011Y03), the Natural Science Foundation of Jiangsu (Grant no. BK2011611), and the Fundamental Research Funds for the Central Universities (Grant no. 2242012R30002) are greatly acknowledged. The authors also would like to acknowledge the Construction Commanding Department of Jiangsu Provincial Yangtze River Highway Bridge and the Structural Health Monitoring Institute of Southeast University.

\section{References}

[1] A. E. Aktan, F. N. Catbas, K. A. Grimmelsman, and C. J. Tsikos, "Issues in infrastructure health monitoring for management," Journal of Engineering Mechanics, vol. 126, no. 7, pp. 711-724, 2000.

[2] J. P. Ou and H. Li, "Recent advances of structural health monitoring in Mainland China," in Proceedings of the ANCER Annual Meeting, 2004. 
[3] H. Li, J. Ou, X. Zhao et al., "Structural health monitoring system for the Shandong Binzhou Yellow River Highway Bridge," Computer-Aided Civil and Infrastructure Engineering, vol. 21, no. 4, pp. 306-317, 2006.

[4] A. S. Kiremidjian, E. G. Straser, T. H. Meng et al., "Structural damage monitoring for civil structures," in Proceedings of the International Workshop on Structural Health Monitoring, pp. 371-382, 1997.

[5] J. M. Ko and Y. Q. Ni, "Structural health monitoring and intelligent vibration control of cable-supported bridges: research and application," KSCE Journal of Civil Engineering, vol. 7, no. 6, pp. 701-716, 2003.

[6] J. P. Ou, "Some recent advances of structural health monitoring systems for civil infrastructure in mainland China," in Proceedings of the Symposium on Network and Center-based Research for Smart Structures Technologies and Earthquake Engineering, pp. 131-144, Tokyo, Japan, 2003.

[7] H. N. Li, D. S. Li, and G. B. Song, "Recent applications of fiber optic sensors to health monitoring in civil engineering," Engineering Structures, vol. 26, no. 11, pp. 1647-1657, 2004.

[8] B. Chen, S. L. Zhao, and P. Y. Li, "Application of HilbertHuang transform in structural health monitoring: a state-ofthe-art review," Mathematical Problems in Engineering, vol. 2014, Article ID 317954, 22 pages, 2014.

[9] B. F. Spencer and S. Cho, "Wireless smart sensor technology for monitoring civil infrastructure: technological developments and full-scale applications," in Proceedings of the World Congress on Advances in Structural Engineering and Mechanics, pp. 18-22, Seoul, Republic of Korea, 2011.

[10] Y. L. Xu and W. S. Chan, "Wind and structural monitoring of long span cable-supported bridges with GPS," in Proceedings of the 7th Asia-Pacific Conference on Wind Engineering (APCWE '09), Taibei, China, November 2009.

[11] B. Chen, Y. L. Xu, and X. Zhao, "Integrated vibration control and health monitoring of building structures: a time-domain approach," Smart Structures and Systems, vol. 6, no. 7, pp. 811833, 2010.

[12] Y. Fujino, M. Murata, S. Okano, and M. Takeguchi, "Monitoring system of the Akashi Kaikyo Bridge and displacement measurement using GPS," in 4th Nondestructive Evaluation of Highways, Utilities, and Pipelines, vol. 3995 of Proceedings of SPIE, pp. 229236, Newport Beach, Calif, USA, March 2000.

[13] S. Nakamura, "GPS measurement of wind-induced suspension bridge girder displacements," Journal of Structural Engineering, vol. 126, no. 12, pp. 1413-1419, 2000.

[14] T. H. Yi, H. N. Li, and M. Gu, "Wavelet based multi-step filtering method for bridge health monitoring using GPS and accelerometer," Smart Structures and Systems, vol. 11, no. 4, pp. 331-348, 2013.

[15] T. H. Yi, H. N. Li, and M. Gu, "Experimental assessment of high-rate GPS receivers for deformation monitoring of bridge," Measurement, vol. 46, no. 1, pp. 420-432, 2013.

[16] T. Guo, A. Q. Li, and J. H. Li, "Fatigue life prediction of welded joints in orthotropic steel decks considering temperature effect and increasing traffic flow," Structural Health Monitoring, vol. 7, no. 3, pp. 189-202, 2008.

[17] H. Wang, A. Li, J. Niu, Z. Zong, and J. Li, "Long-term monitoring of wind characteristics at Sutong Bridge site," Journal of Wind Engineering and Industrial Aerodynamics, vol. 115, pp. 3947, 2013.

[18] H. Wang, A. Li, and J. Li, "Progressive finite element model calibration of a long-span suspension bridge based on ambient vibration and static measurements," Engineering Structures, vol. 32, no. 9, pp. 2546-2556, 2010.

[19] K. D. Hjelmstad and S. Shin, "Damage detection and assessment of structures from static response," Journal of Engineering Mechanics, vol. 123, no. 6, pp. 568-576, 1997.

[20] B. H. Oh and B. S. Jung, "Structural damage assessment with combined data of static and modal tests," Journal of Structural Engineering, vol. 124, no. 8, pp. 956-965, 1998.

[21] R. Brincker, L. Zhang, and P. Andersen, "Modal identification of output-only systems using frequency domain decomposition," Smart Materials and Structures, vol. 10, no. 3, pp. 441-445, 2001.

[22] L. M. Khoo, P. R. Mantena, and P. Jadhav, "Structural damage assessment using vibration modal analysis," Structural Health Monitoring, vol. 3, no. 2, pp. 177-194, 2004.

[23] S. H. Sim, B. F. Spencer, and T. Nagayama, "Multimetric sensing for structural damage detection," Journal of Engineering Mechanics, vol. 137, no. 1, pp. 22-30, 2011.

[24] A. Q. Li, Y. L. Ding, H. Wang, and T. Guo, "Analysis and assessment of bridge health monitoring mass data-progress in research/development of "Structural Health Monitoring"', Science China Technological Sciences, vol. 55, no. 8, pp. 22122224, 2012.

[25] A. E. Aktan, D. N. Farhey, D. L. Brown et al., "Condition assessment for bridge management," Journal of Infrastructure Systems, vol. 2, no. 3, pp. 108-117, 1996.

[26] M. Liu, D. M. Frangopol, and S. Kim, "Bridge system performance assessment from structural health monitoring: a case study," Journal of Structural Engineering, vol. 135, no. 6, pp. 733742, 2009.

[27] H. W. Xia, Y. Q. Ni, K. Y. Wong, and J. M. Ko, "Reliabilitybased condition assessment of in-service bridges using mixture distribution models," Computers \& Structures, vol. 106-107, pp. 204-213, 2012.

[28] Z. W. Chen, Y. L. Xu, Y. Xia, Q. Li, and K. Y. Wong, "Fatigue analysis of long-span suspension bridges under multiple loading: case study," Engineering Structures, vol. 33, no. 12, pp. 32463256, 2011.

[29] Z. W. Chen, Y. L. Xu, and X. M. Wang, "SHMS-based fatigue reliability analysis of multiloading suspension bridges," Journal of Structural Engineering, vol. 138, no. 3, pp. 299-307, 2012.

[30] Z. X. Li, T. H. T. Chan, and T. Q. Zhou, "Accumulative damage near crack tip for welded bridge members: fatigue life determination," Theoretical and Applied Fracture Mechanics, vol. 43, no. 2, pp. 245-260, 2005.

[31] BS5400, B. S. I., Part 10, Code of Practice for Fatigue, 1982. 

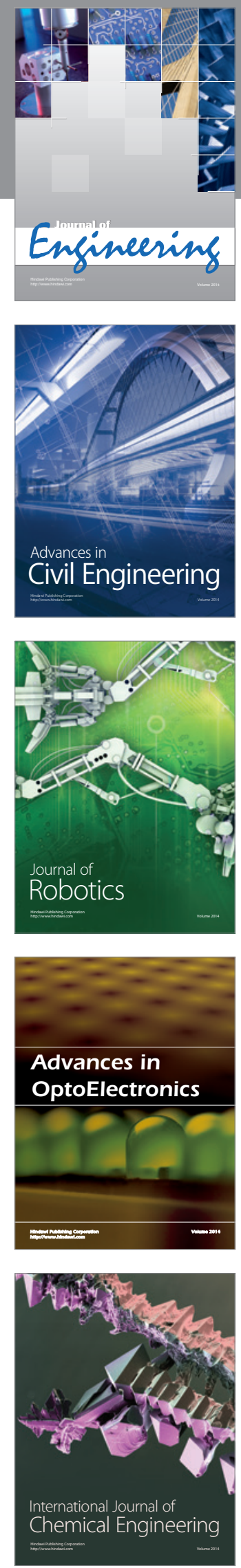

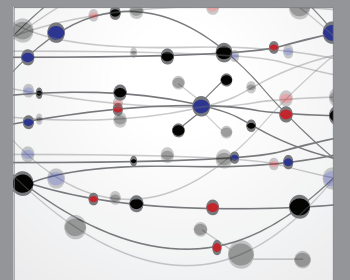

The Scientific World Journal
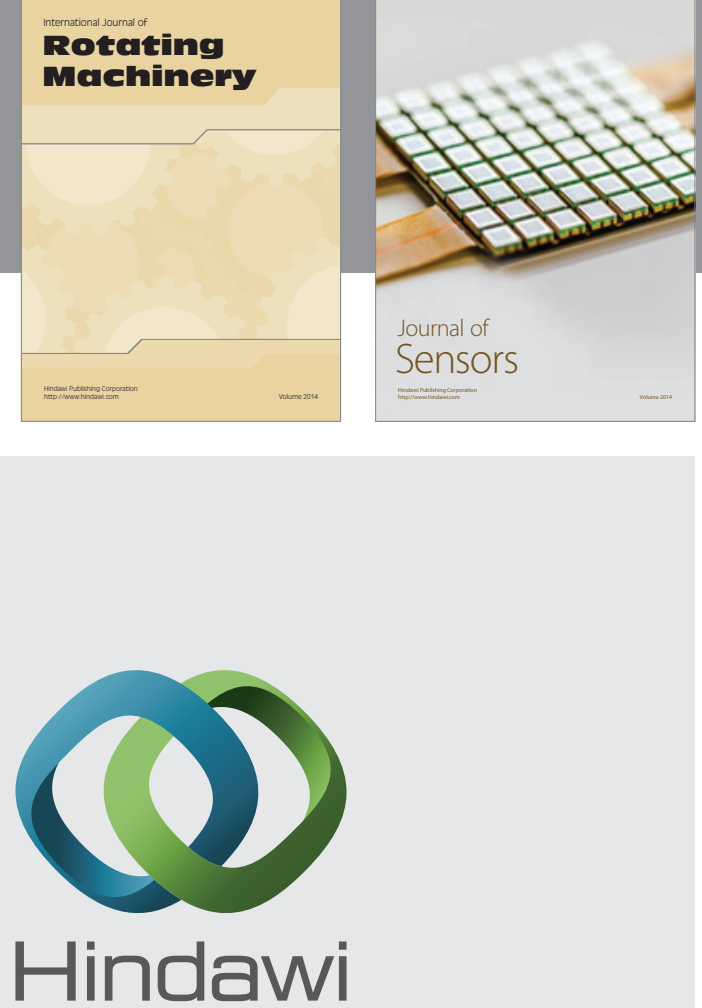

Submit your manuscripts at http://www.hindawi.com
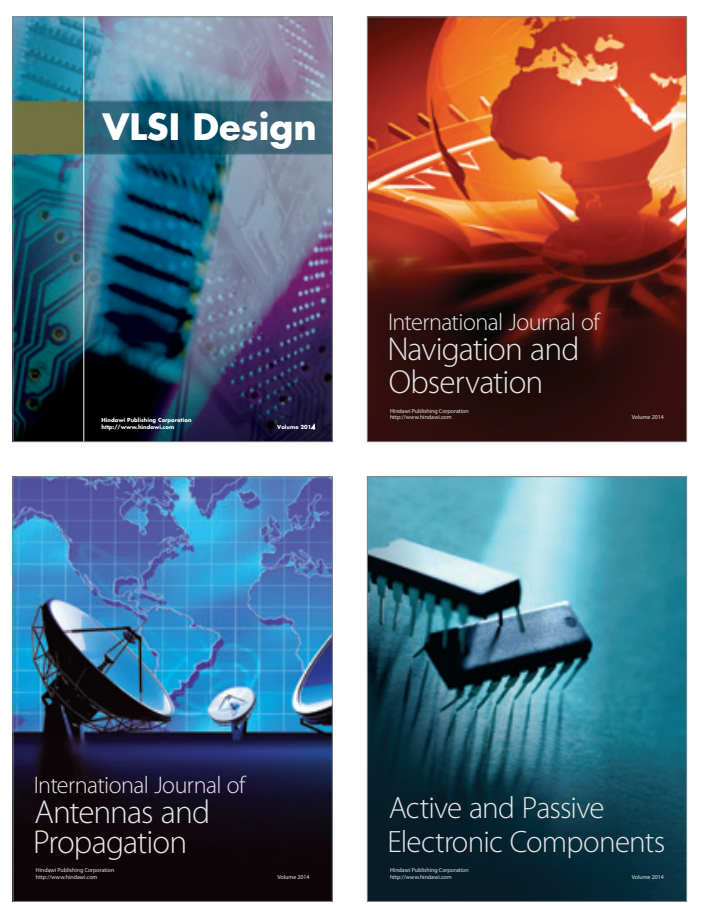
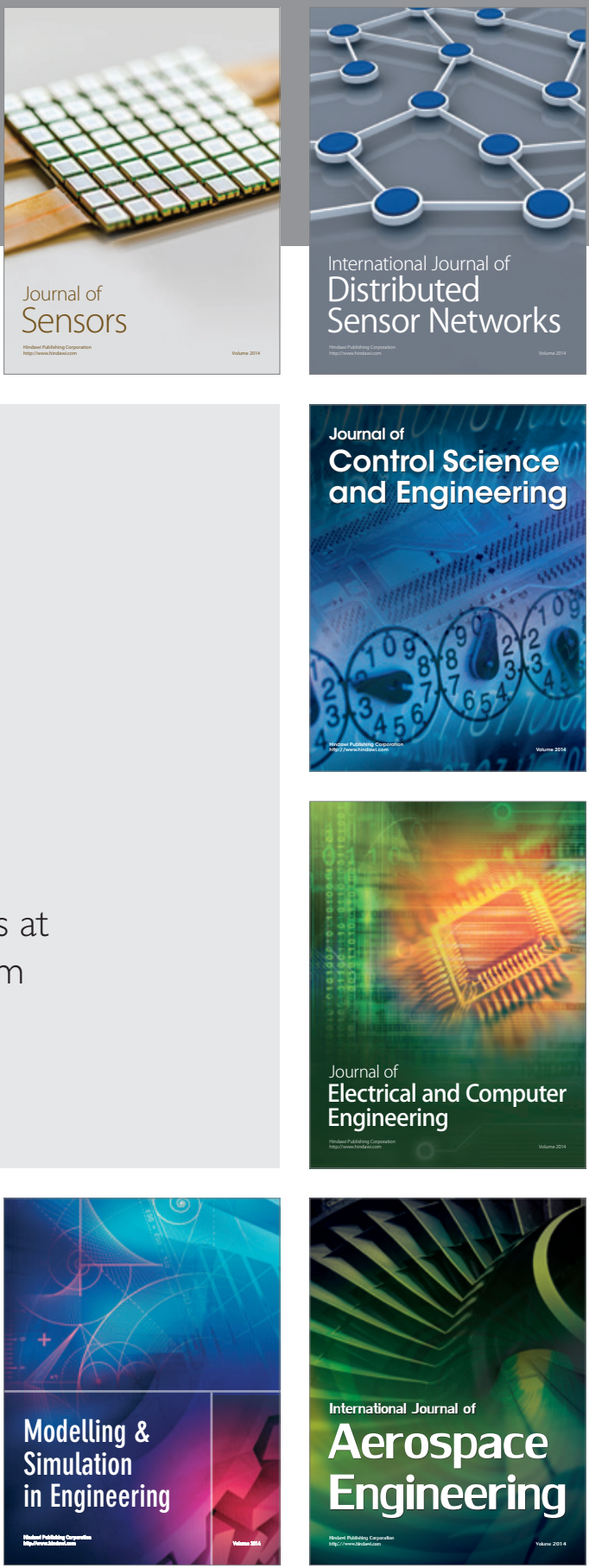

Journal of

Control Science

and Engineering
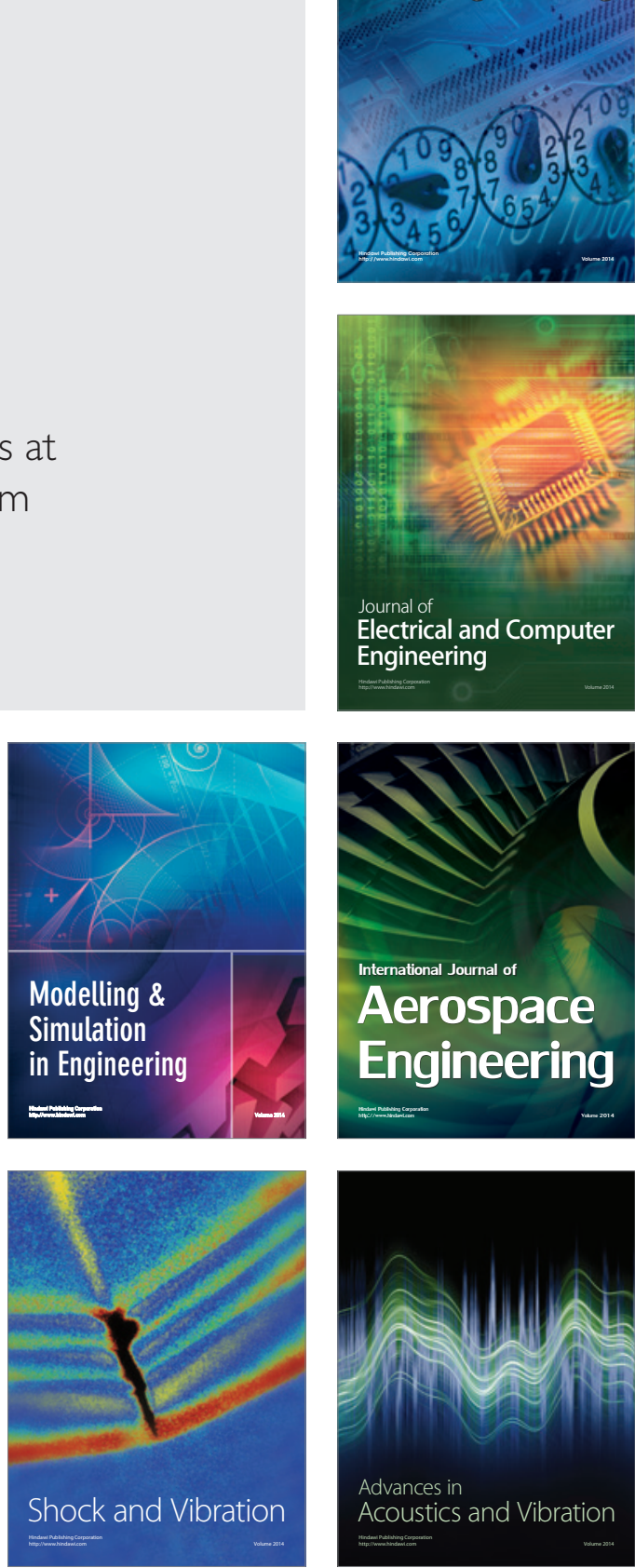